\title{
COMPARATIVE STUDY ON THE IMMUNOHISTOCHEMICAL EXPRESSION OF MASPIN AND CD34 IN NORMAL ORAL MUCOSA, AMELOBLASTOMA AND AMELOBLASTIC CARCINOMA
}

\author{
Omneya M Wahba*, Doaa A Labah** and Shereen A Ali***
}

\begin{abstract}
Background: Maspin is a member of serine protease inhibitor (serpin) superfamily that is considered as an epithelial-specific tumor suppressor. CD34 is transmembrane glycoprotein that could be used as a sensitive vascular marker and useful predictor of tumor progression.

Aim of study: To investigate the expression of maspin and CD34 in normal oral mucosa, different types of ameloblastoma and ameloblastic carcinoma.

Materials and Methods: A total of 25 cases were used in this study and the achieved samples were divided into the following groups; normal gingival mucosa $(n=5)$, unicystic ameloblastoma $(\mathrm{n}=5)$, multicystic ameloblastoma; plexiform and follicular variants $(\mathrm{n}=10$ divided into 5 for each variant) and ameloblastic carcinoma $(n=5)$. To confirm the diagnosis and inclusion of the samples in the study, first 5-micron sections were prepared and were stained using hematoxylin-eosin staining protocol. Then, the blocks were prepared for immunohistochemical staining for maspin and CD34. Statistical analysis was used to compare maspin and CD34 among groups.
\end{abstract}

Results: Immunohistochemical study revealed positive maspin expression in all groups however significant decrease in its expression and tumor progress was detected with the least expression in ameloblastic carcinoma. On the other hand, the vascular endothelial cells within lamina propria were positively stained with CD34 in all groups. Unexpectedly, there was concomitant significant decrease in CD34 expression and tumor progress with the least expression in ameloblastic carcinoma.

Conclusion: Maspin is normally expressed in oral mucosa and further researches are recommended to clarify its role in normal adult odontogenic tissue. Moreover, maspin expression could be used as an accurate determining factor in prognosis and prediction of the odontogenic tumor progress and having superior exactitude in comparison with the angiogenic marker CD34.

KEY WORDS: Maspin, CD34, normal oral mucosa, ameloblastoma, ameloblastic carcinoma

\footnotetext{
* Lecturer, Oral Pathology Department, Faculty of Dentistry, Tanta University

** Lecturer, Oral Biology Department, Faculty of Dentistry, Tanta University

*** Assistant Professor, Oral Medicine Department, Faculty of Dentistry, Tanta University
} 


\section{INTRODUCTION}

Ameloblastoma is an odontogenic tumor that is thought to arise from tooth forming tissues and has commanded considerable attention in the medical and dental literature, since the beginning of $19^{\text {th }}$ century ${ }^{(1,2)}$. Although ameloblastoma is defined as slowly growing benign neoplasm, it demonstrates locally aggressive behavior and a potential lethal nature with a high recurrence rate and is considered the most clinically significant odontogenic tumor ${ }^{(3)}$. In 2005, the World Health Organization classified the benign ameloblastoma into four types namely; solid/multicystic, extra-osseous/peripheral, desmoplastic, and unicystic with the solid/multicystic ameloblastoma can histopathologically be further subdivided into a follicular and a plexiform type. Moreover, the malignant counterparts of ameloblastoma are classified into metastasizing ameloblastoma and ameloblastic carcinoma on the basis of metastatic spread and cytological malignant features ${ }^{(4)}$. The most recent classification of ameloblastic carcinoma was proposed where a primary ameloblastoma is followed by secondary metastasis with histopathological features of malignancy and without evidence of malignancy in the primary localization ${ }^{(5)}$.

Maspin (mammary serine protease inhibitor) is a unique serine protease inhibitor that is originally isolated from mammary epithelial cells and is supposed to possess multifaceted tumor suppressive activities ${ }^{(6,7)}$. Accumulated evidence proposed that maspin down regulation is associated with the development of breast and prostate cancers ${ }^{\left({ }^{8}\right)}$. As well, maspin is shown to be differentially regulated in the progression of other types of tumors including salivary glands and oral squamous cells tumors ${ }^{(9,10)}$.

Beside its putative properties in tumors suppression,maspinisessentialfornormalembryonic development as it was shown that maspin-null mice die at the peri-implantation stage due to a failure of early differentiation events resulting from aberrant adhesion and cell migration ${ }^{(11)}$. Moreover, maspin expressed by active osteoblasts plays an important role in bone matrix maturation ${ }^{(12)}$ and is considered one of most important molecules facilitating the effective accumulation of growth factors and matrix proteins in extracellular matrices during tooth development as well as bone formation ${ }^{(13)}$.

Angiogenesis acts like a double-edged sword, valuable in normal physiologic conditions but uncontrollable and invasive in neoplastic and inflammatory conditions ${ }^{(14)}$. In this regard, CD34 is a vascular marker that is markedly expressed on rapidly proliferating endothelial cells and is associated with metastasis and neoplastic cell infiltration ${ }^{(15)}$. It is a sensitive marker of the vascular endothelium and can be used in the evaluation of microvessel density in neoplasms like ameloblastoma $^{(16)}$. Normally, CD34 is expressed on early lymphopoietic progenitor cells, small vessel endothelial cells, embryonic fibroblasts and some fetal and adult nerve tissue cells ${ }^{(17)}$. Compared to other vascular markers, CD34 staining is stronger and has a lower error rate ${ }^{(18)}$.

Despite of enormous amount of data concerning the expression pattern of maspin and CD34 in various tissues and its relevance to the biological properties of a variety of human cancer cells, little is known about their expression in normal and neoplastic odontogenic tissues. Thus, it's of great importance to study their expression in normal gingival mucosa, different ameloblastomas and ameloblastic carcinoma and explore their efficiency as dependable prognostic markers of odontogenic neoplasms.

\section{MATERIALS AND METHODS}

A total of 25 cases were used in this study including normal odontogenic mucosal tissue that were taken from the normal adult gingiva as a part of gingivectomy procedure performed in Department of Oral Medicine, Faculty of Dentistry, Tanta University and diagnosed cases of ameloblastoma and ameloblastic carcinoma were retrieved from archives of the Department of Oral Pathology, Faculty of Dentistry, Tanta University. The study groups comprised of normal gingival mucosa 
$(\mathrm{n}=5)$, unicystic ameloblastoma $(\mathrm{n}=5)$, multicystic ameloblastoma; plexiform and follicular variants ( $\mathrm{n}=10$ divided into 5 for each variant) and ameloblastic carcinoma $(n=5)$.

To confirm the diagnosis and inclusion of the samples in the study, first 5-micron sections were prepared and were stained using hematoxylin-eosin staining protocol. The diagnosis was then confirmed by two pathologists. Sections with enough tissue with suitable fixation were selected and those with inflammation and hemorrhage and insufficient tissue and incisional biopsy were excluded from the study. Afterward, the blocks of normal gingiva, ameloblastoma and ameloblastic carcinoma were prepared for immunohistochemical staining for maspin and CD34

\section{Immunohistochemistry}

For the immunohistochemical staining, fourmicron sections were prepared from each paraffin block and were deparaffinized in xylene and dehydrated in graded alcohol series. To block the internal peroxidase activity they were placed in hydrogen peroxide $(3 \%)$ in phosphate buffer. Antigen retrieval was done in a microwave oven (Panasonic 1380W) for 10 minutes, under the pressure of 2 atmosphere in 120 degree centigrade. Further incubations with pre-diluted ready to use primary mouse monoclonal antibody, anti maspin Ab-1(Clone EAW24, lab vision corporation, Fermont, USA) and anti CD34(QBend 10, A/S, Glostrup, DAKO, Denmark) was used asthe primary antibody for 30 minutes and was incubated in a moist chamber at room temperature $(24 \mathrm{~h})$ with a working dilution 1:50, followed by the application of secondary antibody (for 15 minutes), DAB (to produce brown staining), and Meyer's hematoxylin (for background staining). The samples were placed in phosphate buffer saline (PBS) after each mentioned step. Prostate gland and placenta was the positive control for maspin and CD34 respectively according to the manufacturer's instructions. The negative controlwas obtained by the replacement of primary antibody with PBS

\section{Assessment of immunohistochemistry stained sections}

Presence of brown colored reaction localized to the nucleus or cytoplasm was considered as positive reaction. The intensity of the immunostaining was classified as negative, weak or strong from three fields in a blinded analysis performed by two independent pathologists using a conventional diagnostic microscope (Eclipse 80i, Nikon, Tokyo, Japan), and further image analysis was done with the Image J software (version 4.10.03, Nikon, Tokyo, Japan).

\section{Statistical analysis}

For statistical analysis, all measurement data were presented as mean \pm standard deviation. All statistical analyses were performed using oneway analysis of variance (ANOVA) followed by Dunnett's post hoc test to reveal statistical significance of difference. Values of $\mathrm{P}<0.05$ indicated a statistically significant difference.

\section{RESULTS}

\section{Histopathological findings}

Normal gingival mucosa revealed lamina propria covered by parakeratinized epithelium; possessing the classical appearance of basal, spinous, granular cell layers and cornified cell layer that retained many pyknotic nuclei (Fig. 1,a). Unicysticameloblastomas showed a single cyst lined by ameloblastic epithelium with hyperchromatic polarized basal layer (ameloblast like cells) and the above cells are stellate reticulum like cells (Fig. 1,b). Plexiformameloblastoma, a variant of multicysticameloblastoma, showed plexuses or networks of odontogenic epithelium in a fibrous connective tissue stroma and composed of two types of the cells; peripherally arranged ameloblast like cells and centrally loosely arranged stellate reticulum like cells (Fig.1,c). Similar to plexiform type, follicular ameloblastoma composed of the same two types of the cells; ameloblast like cells and stellate reticulum like cells but arranged in follicles instead of being arranged in plexuses (Fig. $1, d)$. Ameloblastic carcinoma formed of nests of 
cells with the distinctive features of ameloblastic differentiation: peripheral palisading of basaloid cells coupled with dyscohesiveness of the cells in the middle of the nests created the typical stellate reticulum arrangement. The degree of mitotic activity, hyperchromatism, cellular and nuclear pleomorphism, increase nuclear/cytoplasm ratio, squamous metaplasia and presence of necrotic foci are characters of the tumor supported the malignant nature of this ameloblastic neoplasm (Fig. 1, e).

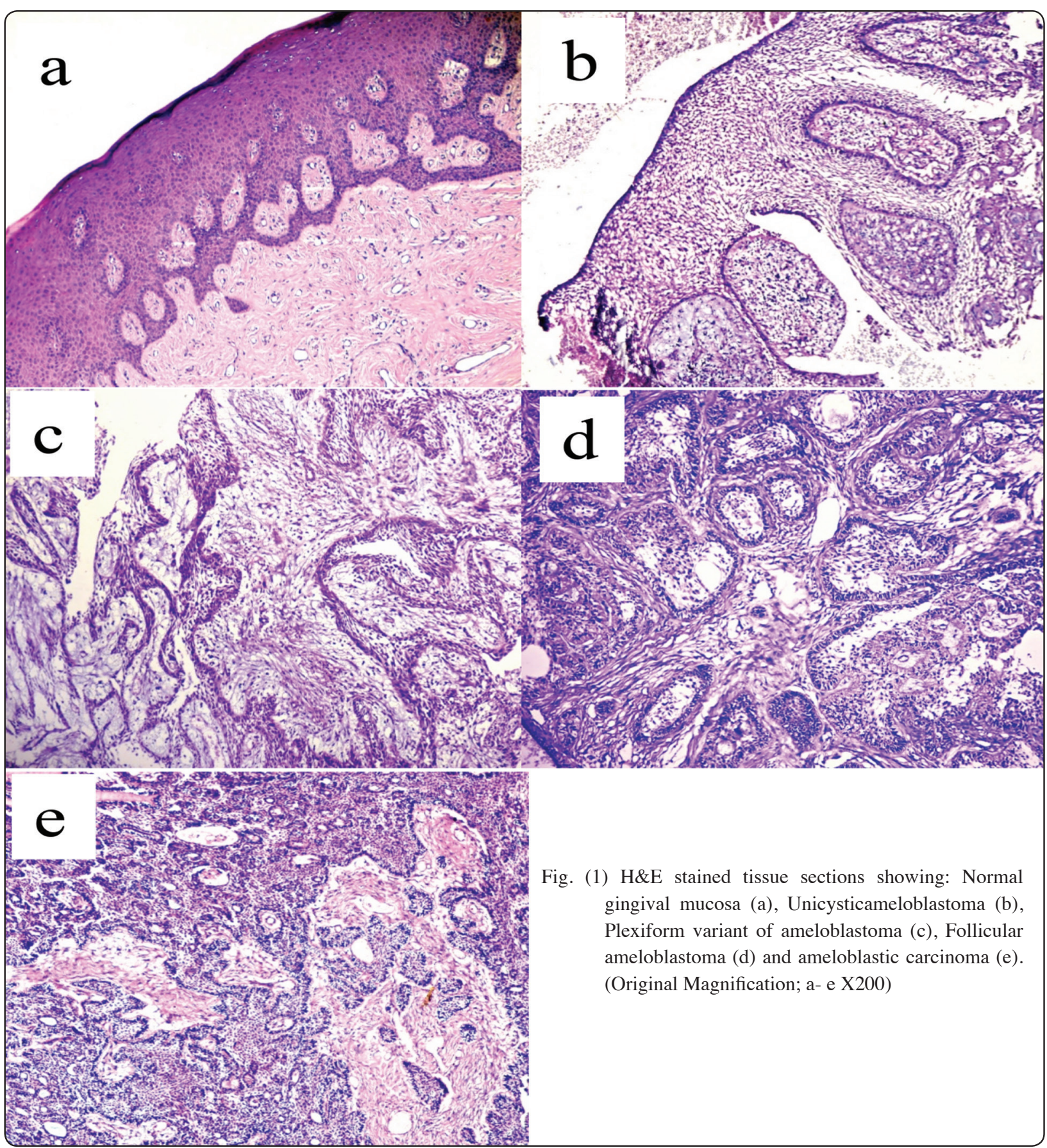




\section{Maspin immunohistochemical findings}

In normal mucosa, positive nuclear maspin expression was detected in the normal epithelial cells with stronger reactivity in basal and prickle cell layers (Fig. 2,a). On the other hand, Unicysticameloblastomas showed evident maspin reactivity in peripheral columnar or cuboidal cells (ameloblast like cells) and less reactivity in central polyhedral cells (stellate reticulum like cells) (Fig. 2,b). Plexiform and follicular ameloblastomas showed positive maspin reaction in ameloblast like cells and stellate reticulum like cells however plexiform variant showed more reactivity to maspin than follicular one (Fig. 2,c\&d). Interestingly, ameloblastic carcinomas showed weak reactivity for maspin in some neoplastic cells (Fig. 2, e).

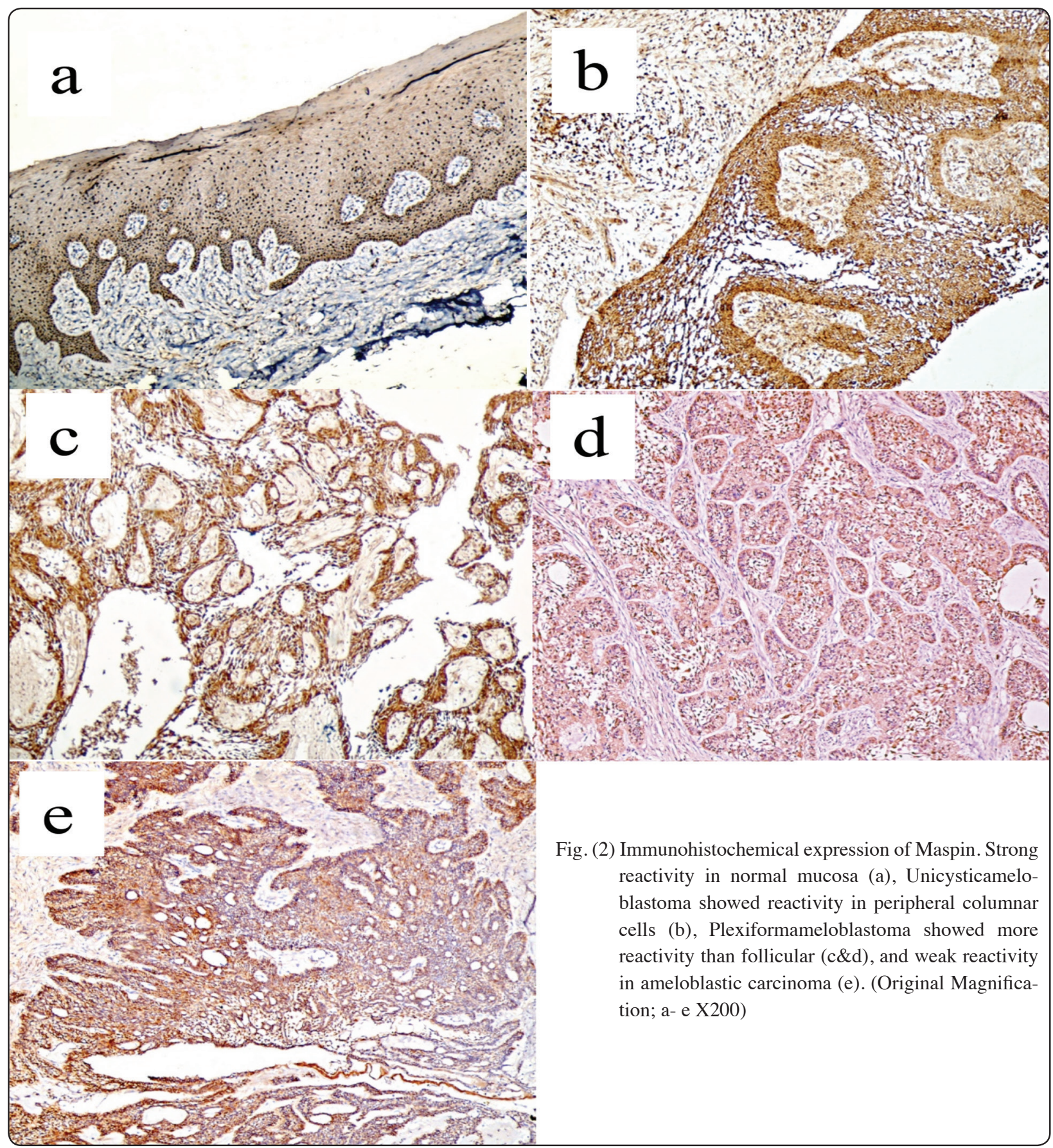




\section{CD34 immunohistochemical findings:}

The vascular endothelial cells within lamina propria were positively stained with CD34 in all groups. Apparently in normal mucosa and unicysticameloblastoma, the blood vessels were in high number and small in size (Fig. $3, \mathrm{a} \&$ b).
However in multicystic variants, plexiform and follicular, the blood vessels were more dilated and more distributed in less numbers with the follicular variant exhibited more dilated blood vessels than plexiform variant(Fig. 3, c \& d). On the other hand, ameloblastic carcinoma showed few scattered blood vessels in the stroma (Fig. 3, e).

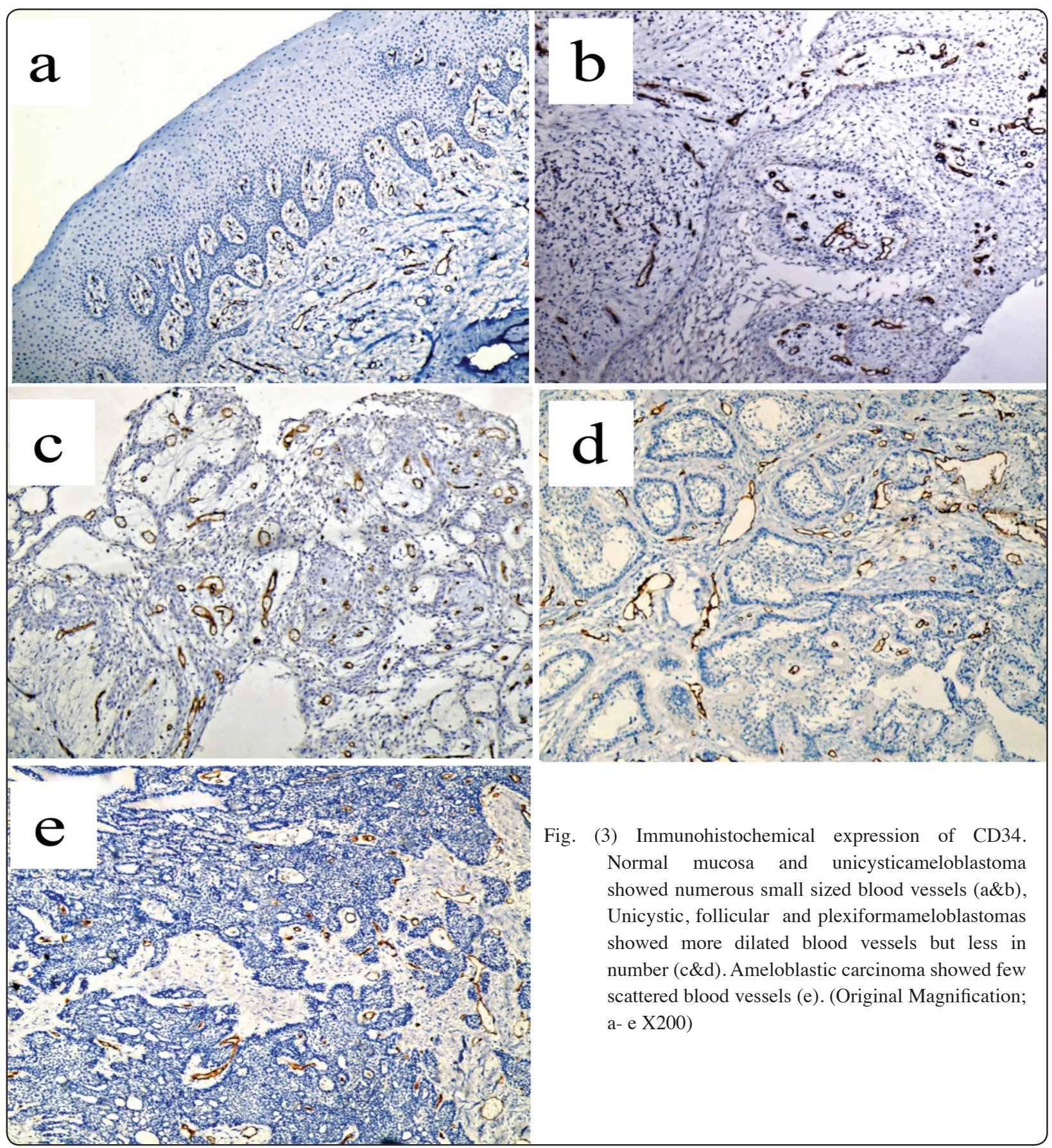




\section{Statistical results}

Statistical analysis of maspin expression among various groups revealed that there was no significance difference in maspin expression between normal tissue and unicysticameloblastoma but in comparison between its expression among other groups revealed significant differences (Table $1 \&$ Fig. 4).
On the other hand, statistical analysis revealed concomitant significant decrease in the CD34 expression and tumor progress with the least expression in ameloblasticcarcinoma. Moreover, no significance difference was found between plexiform and follicular ameloblastoma. Also, no significance difference between follicular ameloblastoma and ameloblastic carcinoma (Table 2, Fig. 5)

TABLE (1) Maspin expression in normal mucosa, ameloblastomas and ameloblastic carcinoma

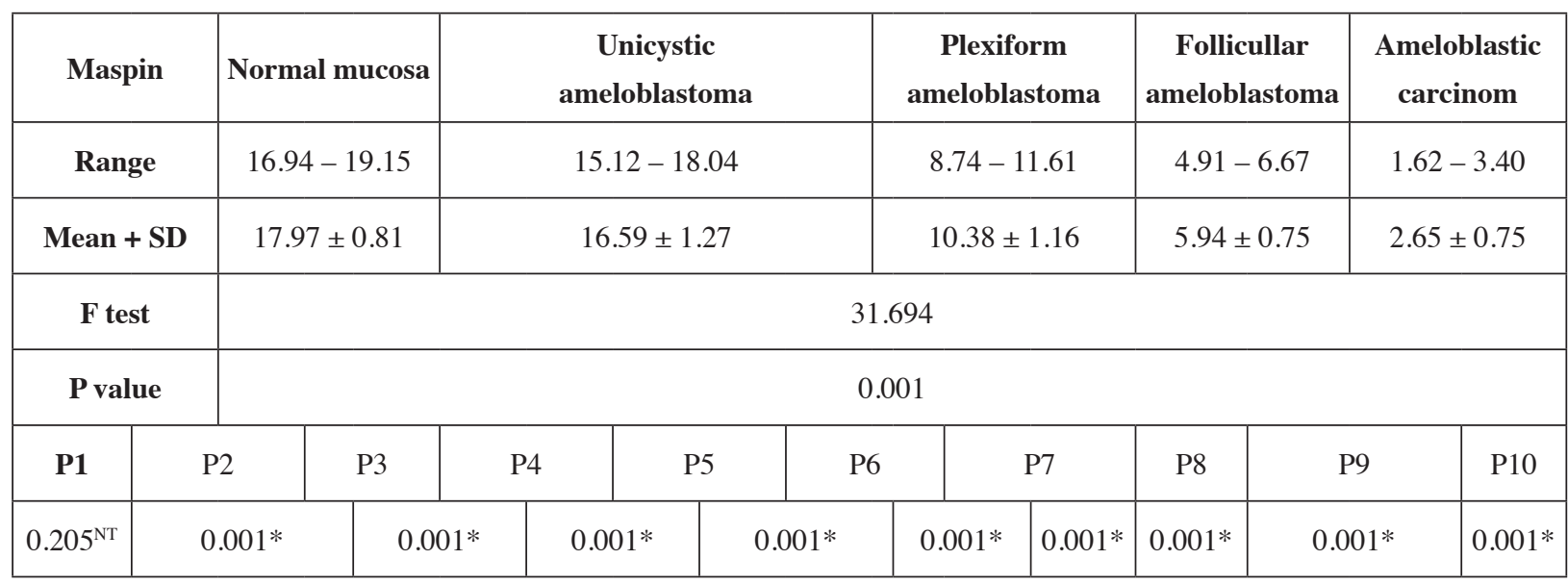

* significant ${ }^{N T}$ non significant

TABLE (2) CD34 expression in normal mucosa, ameloblastomas and ameloblastic carcinoma

\begin{tabular}{|c|c|c|c|c|c|c|c|c|c|c|}
\hline \multicolumn{2}{|c|}{ CD34 } & \multicolumn{2}{|c|}{$\begin{array}{l}\text { Normal } \\
\text { Mucosa }\end{array}$} & $\begin{array}{c}\text { Unicystic } \\
\text { ameloblastoma }\end{array}$ & \multicolumn{2}{|c|}{$\begin{array}{c}\text { Plexiform } \\
\text { ameloblastoma }\end{array}$} & \multicolumn{2}{|c|}{$\begin{array}{c}\text { Follicular } \\
\text { ameloblastoma }\end{array}$} & \multicolumn{2}{|c|}{$\begin{array}{c}\text { Ameloblastic } \\
\text { carcinoma }\end{array}$} \\
\hline \multicolumn{2}{|c|}{ Range } & \multicolumn{2}{|c|}{$4.31-6.04$} & $2.41-4.51$ & \multicolumn{2}{|c|}{$1.30-2.62$} & \multicolumn{2}{|c|}{$0.63-1.40$} & \multicolumn{2}{|c|}{$0.32-0.64$} \\
\hline \multicolumn{2}{|c|}{ Mean + SD } & \multicolumn{2}{|c|}{$5.09 \pm 0.68$} & $3.50 \pm 0.81$ & \multicolumn{2}{|c|}{$1.98 \pm 0.49$} & \multicolumn{2}{|c|}{$0.99 \pm 0.33$} & \multicolumn{2}{|c|}{$0.46 \pm 0.12$} \\
\hline \multicolumn{2}{|c|}{ F test } & \multicolumn{9}{|c|}{20.443} \\
\hline \multicolumn{2}{|c|}{ P value } & \multicolumn{9}{|c|}{0.001} \\
\hline P1 & \multicolumn{2}{|c|}{$\mathrm{P} 2$} & P3 & P5 & P6 & P7 & P8 & \multicolumn{2}{|c|}{ P9 } & P10 \\
\hline $0.001 *$ & \multicolumn{2}{|c|}{$0.001^{*}$} & $0.001 *$ & $0.002 *$ & $0.001 *$ & $0.001 *$ & $0.066^{\mathrm{NT}}$ & \multicolumn{2}{|c|}{$0.002 *$} & $0.546^{\mathrm{NT}}$ \\
\hline
\end{tabular}

\footnotetext{
* significant $\quad{ }^{N T}$ non significant
} 


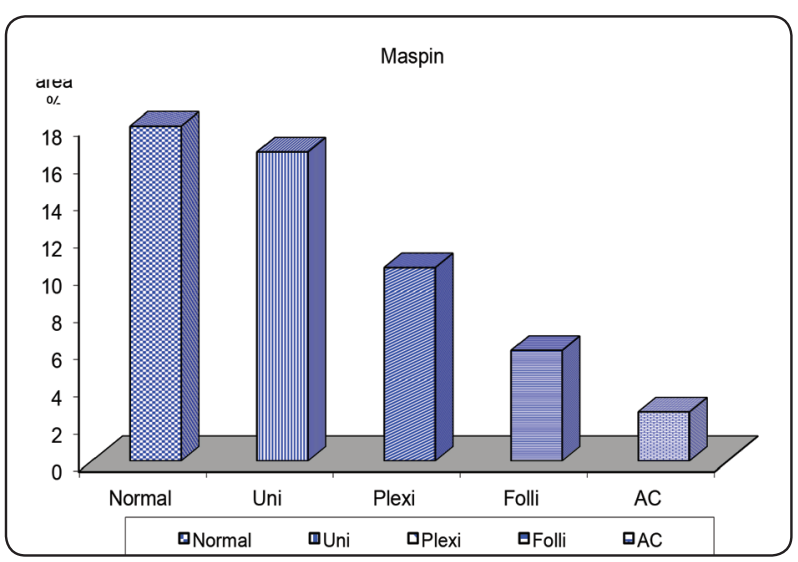

Fig (4) Histogram showing mean values of area $\%$ of maspin immunoexpression in normal mucosa, ameloblastomas and ameloblastic carcinoma

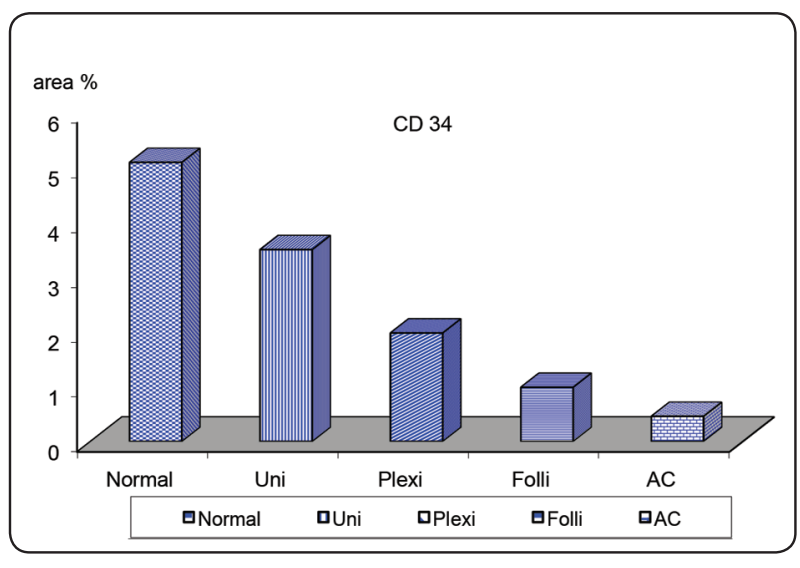

Fig (5) Histogram showing mean values of area \% of CD34 immunoexpression in normal mucosa, ameloblastomas and ameloblastic

\section{DISCUSSION}

The present study addressed three research points. First; to discriminate maspin expression in normal and neoplastic odontogenic tissues. Second; to distinguish angiogenic marker CD34 expression in normal and neoplastic odontogenic tissues. Third; to compare between maspin and CD34 as reliable prognostic markers of odontogenic neoplasms.

In the current study, normal oral mucosa showed strong nuclear maspin reactivity in basal and prickle epithelial cell layers. This finding was in agreement with Lockett et al. (2006) ${ }^{(19)}$ who found that in normal prostate, the basal epithelial cells uniformly express maspin at high level mostly in the nuclei.
Although few researches confirmed the importance of maspin for normal development, the role of maspin in normal adult tissue is still unclear but it was found that maspin could function as a transcription factor regulating gene expression (Kaplun et al., 2012) ${ }^{(20)}$. Moreover, Ellis ZK (2006) ${ }^{(21)}$ proposed that maspin is a central component of epithelial cells, engaged in a network of interactions with wide variety of proteins and regulating the epithelial homeostasis of many tissues.

The present results showed that unicystic ameloblastoma exhibited stronger maspin reactivity than multicystic ameloblastoma. On the other hand, ameloblastic carcinoma showed weak reactivity for maspin compared with unicystic and multicystic ameloblastoma. This consensus that maspin expression predicts a better prognosis (Xia, 2000) (22). In contrary, Kumamoto and Ooya (2007) (23) suggested that aberrant maspin expression in neoplastic cells of ameloblastic tumors might be involved in oncogenesis and malignant potential of odontogenic epithelium.

In normal epithelial tissues, we found that the intracellular maspin is predominantly nuclear however cytoplasmic expression was noticed with varying degrees in ameloblastomas. Interestingly, accumulated clinical evidence nuclear retention of maspin is correlated with better overall patient survival (Pierson et al., 2002) ${ }^{(24)}$. Conversely, the shift in subcellular localization of maspin from the nucleus to the cytoplasm is associated with a gain of function during tumor progression (Lonardo et al., 2005) ${ }^{(25)}$

In accordance with immunohistochemical observations, statistical analysis of maspin expression among various groups revealed that there was no significance difference in maspin expression between normal tissue and unicystic ameloblastoma, but in comparison between its expressions among other groups revealed significant decrease. These results could be linked to the previously reported tumor suppressor capability of maspin through decreasing cell migration, invasion, proliferation 
while increasing apoptosis and adhesion (Sheng et al., $1998{ }^{(26)}$ and Yoshida et al., $\left.2001{ }^{(27)}\right)$.

Several studies showed that maspin inhibits cell motility by enhancing cell adhesion. there are two proposed pathways utilized by maspin to increase cell-extracellular matrix (ECM) adhesion; the plasminogen activation system and b1 integrin signaling ${ }^{(28-32)}$

The plasminogen activation system is believed to be a central player in several different processes important for tumor progression and metastasis ${ }^{(33-35)}$. In this system urokinase-type plasminogen activator (UPA), a serine protease, binds to its receptor (UPAR) and readily activates plasminogen to initiate a protease cascade resulting in localized ECM degradation for the purpose of cell migration (36). It has been suggested that maspin integrates into the plasminogen activation system and reducing uPA activity by internalizing the maspin-uPAuPAR complex. Thus maspin inhibits tumour cell migration and invasion by enhancing cell adhesion to ECM protein fibronectin and strengthening mature focal adhesion contacts, thus maspin may directly inhibit ECM degradation ${ }^{(37)}$.

The second proposed cell adhesion pathway involves maspin associating with b1 integrin, thus, altering integrin-mediated signaling thus stimulate focal adhesion contacts and inhibit cell detachement

Accumulated evidences suggested that the inhibitory function of maspin on tumor growth is at least in a part due to increased apoptosis. The apoptotic role of maspin might relay on that it is the only endogenous inhibitor of histone deacetylase I (HDAC I) thus inhibiting the proliferative role of HDAC I. Moreover, maspin-mediated tumor cell apoptosis could be through the mitochondrial death pathway since mechanistic studies showed that maspin might induce tumor cell apoptosis by altering the mitochondrial permeability transition and initiating apoptotic degradation ${ }^{(38)}$. In contrary to these results, Teoh et al. (2013) ${ }^{(39)}$ who suggested that maspin is not required for normal development or tumour suppression.
On the other hand in the present work, the vascular endothelial cells within the connective tissue were positively stained by the angiogenic marker CD34 in all groups but in varying degrees. This could be explained by the fact that the blood vessels in stroma are one of the essential factors of epithelial growth (Kumar et al., 2005) ${ }^{(14)}$. Moreover, the growth, aggressive behavior, and metastasis of a tumor need nutritional substances and oxygen that is provided by blood vessels (Inda et al., 2007) ${ }^{(40)}$. Unexpectedly, statistical analysis revealed concomitant significant decrease in the CD34 expression and tumor progress with the least expression in ameloblastic carcinoma. This could be explained by that the reduction in CD34 expression in stromal tissue is associated with increased expression of stromal actin in cancers (Hvingel et al., 2012) ${ }^{(41)}$. This is coincident with the result of Roy and Garg (2013) ${ }^{(42)}$ who found an increased expression of alpha smooth muscle actin in ameloblastic carcinoma.

An interesting finding in multicystic variants in the current study was that the blood vessels were more dilated than other groups. Moreover, follicular variant exhibited more dilated blood vessels than plexiform variant. This is in contrast with the results of Seifi et al., (2011) ${ }^{(34)}$ who found that the blood vessels in high numbers and smaller size were abundant in follicular ameloblastoma and were more dilated and more distributed in less numbers in plexiform ameloblastoma.

In conclusion, maspin is normally expressed in adult oral mucosa and further researches are recommended to clarify its role in normal adult odontogenic tissue. Moreover, maspin expression could be used as a precise determining factor in prognosis and prediction of the odontogenic tumor progress and having superior accuracy in comparison with the angiogenic marker CD34. Most interesting, a remarkable advantage of maspin is its ability to offer a unique opportunity to block tumor invasion and metastasis hence it is of great importance to recommend development of a maspin- based anti cancer therapy. 


\section{REFERENCES}

1. Reichart, P.A., Philipsen, H.P. and Sonner, S.: Ameloblastoma: Biological profile of 3677 cases. Eur J Cancer B Oral Oncol., 31B: 86-99, 1995.

2. Brannon, R.B.: The odontogenickeratocyst: A clinicopathologic study of 312 cases. Part II: Histologic features. Oral Surg Oral Med Oral Pathol., 43:233-55, 1977.

3. Gardner, D.G. and Pecak, A.M.: The treatment of ameloblastoma based on pathologic and anatomic principles. Cancer, 46:2514-2519, 1980.

4. Gardner, D.G. and Shear, M.: In: Barnes, L., Eveson, J.W., Reichart, P., Sidransky, D., editors. World Health Organization classification of tumor: pathology and genetics, head and neck tumors. Lyon: IARC Press, 296$300,2005$.

5. Kruse, A., Zwahlen, R.A. and Grätz, K.A.: New classification of maxillary ameloblastic carcinoma in based on anevidence-based literature review over the last 60 years. Head \& Neck Oncology, 1:31, 2009.

6. Zou, Z., Anisowicz, A., Hendrix, M.J., Thor, A., Neveu, M., Sheng, S., RaWdi, K., Seftor, E. and Sager, R.: Maspin, a serpin with tumor-suppressing activity in human mammary epithelial cells. Science, 263:526-529, 1994.

7. Shi, H.Y., Zhang, W., Liang, .R, Abraham, S., Kittrell, F.S., Midina, D. and Shang, M.: Blocking tumor growth, invasion, and metastasis by maspin in a synergenic breast cancer model. Cancer Res., 61:6945-6951, 2001.

8. Zou, Z., Zhang, W., Young, D., Gleave, M.G., Rennie, P., Connell, T., Connelly, R., Moul, J., Srivastava, S. and Sesterhenn, I.: Maspin expression profile in human prostate cancer $(\mathrm{CaP})$ and in vitro induction of Maspin expression by androgen ablation. Clin Cancer Res., 8:1172-1177, 2002.

9. Marioni, G., Gaio, E., Giacomelli, L., Bertolin, A., Alessandro, E., Stramare, R., Facco, R., Staffieri, A. and Blandamura, S.: MASPIN subcellular localization and expression in oral cavity squamous cell carcinoma. European Archives of Oto-Rhino-aryngology, 265:97$104,2008$.

10. Reshma, V., Rao, K., Priya, N. S., Umadevi, H. S., Smitha, T. and Sheethal, H.S.: Expression of maspin in benign and malignant salivary gland tumors: An immunohistochemical study. Indian J Dent Res., 25:346-351, 2014.

11. Gao, F., Shi, H. Y., Daughty, C., Cella, N., and Zhang, M.: Maspin plays an essential role in early embryonic development. Development, 131, 1479-1489, 2004.
12. Tokuyama, R., Satomura, K., Maeda, E., Kudoh, K., Yamasaki, Y. and Nagayama, M.: Maspin is involved in bone matrix maturation by enhancing the accumulation of latent TGF-b. J Bone Miner Res., 22:1581-1591, 2007.

13. Davaadorj, P., Tokuyama, R., Ide, S., Tadokoro, S., Kudoh, K. and Satomura, K.: Possible involvement of maspin in tooth development. Histochem. Cell Biol., 134:603-614, 2010.

14. Kumar, D.V., Shaktidar, P.R., Hemavathy, S. and Sahana, N.S.: Review on angiogenesis and its importance in tumor progression. IOSR-JDMS, 13: 103-108, 2004.

15. Nagatsuka, H., Hibi, K., Gunduz, M., Tsujigiwa, H., Tamamura, R.and Sugahara. T.: Various immunostaining patterns of CD31, CD34 and Endoglin and their relationship with lymph node metastasis in oral squamous cell carcinomas. J. Oral Pathol. Med., 34:70-6, 2005.

16. Kumamoto, H., Ohki, K. and Ooya, K.: Association between vascular endothelial growth factor (VEGF) expression and tumor angiogenesis in ameloblastomas. J. Oral Pathol. Med., 31:28-34, 2002.

17. Sherlin, J., Natesan, A., Ram, P., Ramani, P., and Thiruvenkadam, C.: Immunohistochemical profiling of ameloblastomas using cytokeratin, vimentin, smooth muscle actin, CD34 and S100. Ann. Maxillofac. Surg., 3: $51-57,2013$

18. Leek, R.D.: The prognostic role of angiogenesis in breast cancer. Anticancer Res., 21: 4325-433, 2001.

19. Lockett, J., Yin, S., Li, X., Meng, Y. and Sheng, s.: Tumor suppressive maspin and epithelial homeostasis. J. Cell Biochem., 97: 651-660, 2006.

20. Kaplun, A., Dzinic, S., Bernardo, M. and Sheng, S.: Tumor suppressor maspin as a rheostate in HDAC regulation to achieve the fine- tuning of epithelial homeostasis. Crit. Rev. Eukaryot. Gene Expr., 22 : 249-258, 2012.

21. Ellis, Z. K.: Maspin: the new frontier. Clin. Cancer Res., 12:7279-7283, 2006.

22. Xia, W., Lau, Y.K., Hu, M.C., Li, L., Johnston, D.A., Sheng, S., El-Naggar, A. and Hung, M.C.: High tumoral maspin expression is associated with improved survival of patients with oral squamous cell carcinoma. Oncogene, 19:2398-2403, 2000.

23. Kumamoto, H. and Ooya, K.: Immunohistochemical detection of uPA, uPAR, PAI-1, and maspin in ameloblastic tumors. J. Oral Pathol. Med., 36:488-94, 2007.

24. Pierson, C.R., McGowen, R., Grignon, D., Sakr, W. and Dey, J.: Maspin is up-regulated in premalignant prostate epithelia. Prostate, 53: 255-262, 2002. 
25. Lonardo, F., Li, X.H., Siddiq, F., Singh, R. and At-Abbadi, M.: Maspin nuclear localization is linked to favorable morphological features in pulmonary adenocarcinoma. Lung Cancer, 51: 31-39, 2006.

26. Sheng, S.J., Truong, B., Fredrickson, D., Wu, R.L. and Pardee, A.B.: Tissue-type plasminogen activator is a target of the tumor suppressor gene maspin. Proceedings of the National Academy of Sciences of the United States of America, 95: 499-504, 1998.

27. Yoshida, M., Furumai, R., Nishiyama, M., Komatsu, Y. and Nishino, N.: Histone deacetylase as a new target for cancer chemotherapy. Cancer Chemotherapy and Pharmacology, 48: S20-S26, 2001.

28. Cella, N., Contreras, A., Latha, K., Rosen, J. M., and Zhang, M.: Maspin is physically associated with $\beta 1$ integrin regulating cell adhesion in mammary epithelial cells. FASEB J., 20: 1510-1512, 2006.

29. Al-Ayyoubi, M., Schwartz, B. S. and Gettins, P. G.: Maspin binds to urokinase-type and tissue-type plasminogen activator through exosite- exosite interactions. J. Biol. Chem., 282: 19502-19509, 2007.

30. Yin, S., Lockett, J., Meng, Y., Biliran, H., Jr., Blouse, G. E., Li, X., Reddy, N., Zhao, Z., Lin, X., Anagli, J., Cher, M. L. and Sheng, S.: Maspin retards cell detachment via a novel interaction with the urokinase-type plasminogen activator/urokinase-type plasminogen activator receptor system. Cancer Res., 66: 4173-4181, 2006.

31. Bass, R., Wagstaff, L., Ravenhill, L. and Ellis, V.: Binding of extracellular maspin to beta 1 integrins inhibits vascular smooth muscle cell migration J. Biol. Chem., 284: 27712$27720,2009$.

32. Endsley, M., Hu, Y., Deng, Y., He, X., Warejcka, D.,Twining, S., Gonias, S. and Zhang, M.. Maspin, the molecular bridge between the plasminogen activator system and integrin that facilitates cell adhesion. J. Biol. Chem., 28: 24599-24607, 2011.

33. Andreasen, P. A., Egelund, R. and Petersen, H. H.: The plasminogen activation system in tumor growth, invasion, and metastasis. Cell. Mol. Life Sci., 57: 25-40, 2000.
34. Blasi, F. and Carmeliet, P.: uPAR: a versatile signalling orchestrator. Nat. Rev. Mol. Cell Biol., 3: 932-943, 2002.

35. Mazar,A. P., Henkin, J. and Goldfarb, R. H.: The urokinase plasminogen activator system in cancer: implications for tumor angiogenesis and metastasis. Angiogenesis, 3: 15$32,1999$.

36. Ellis, V., Behrendt, N. and Danø, K.: Plasminogen activation by receptor-bound urokinase. A kinetic study with both cell-associated and isolated receptor. J. Biol. Chem., 266:12752-12758, 1991.

37. Yin, S., Lockett, J., Meng, Y., Biliran, H.R., Blouse, G., Lin, X., Anagli, J., Reddy, N., Zhao, Z., Cher, M.L. and Sheng, S.: Maspin retards cell detachment via a novel interaction with the uPA/uPAR system. Cancer Res., 66: 4173-81, 2006.

38. Latha, K., Zhang, W., Cella, N., Shi, H. Y. and Zhang, M.: Maspin mediates increased tumor cell apoptosis upon induction of the mitochondrial permeability transition. Mol. Cell Biol., 25:1737 -1748, 2005.

39. Teoh, S.Y., Vieusseux, J., Prakash, M., Berkowicz, S., Luu, J., Bird, C., Law, R., Rosado, C., Price,J., Whisstock, J. and Bird, P.: Maspin is not required for embryonic development or tumour suppression. Nat. Commun., 5:3164, 2013.

40. Inda, A.M., Andrini, L.B. and Garcia, M.N.: Evaluation of angiogenesis with the expression of VEGF and CD34 in human non- small cell lung cancer. J. Exp. Clin. Cancer Res., 26: 375-78, 2007.

41. Hvingel, B., Lieng, M., Roald, B. and Ørbo, A.: Vascular markers CD31, CD34, actin, VEGFB, and VEGFR2, are prognostic markers for malignant development in benign endometrial polyps. OJOG., 2: 18-26, 2012.

42. Roy,S. and Garg, V.: Alpha smooth muscle actin expression in a case of ameloblastic carcinoma: a Case report. J Oral Maxillofac Res., 4: 2, 2013.

43. Seifi, S., Shafaie, S. and Ghadiri S.: Microvessel density in follicular cysts, keratocystic odontogenic tumours and ameloblastomas. Asian Pacific J. Cancer Prev., 12: 351$356,2011$. 